\title{
Determining e-learning success factor in higher education based on user perspective using Fuzzy AHP
}

\author{
Rini Anggrainingsih*, Muhammad Zuhrul Umam, and Haryono Setiadi \\ Informatics Dept, Sebelas Maret University, J1 Ir Sutami 36 A, Kentingan, Surakarta, Indonesia 57126
}

\begin{abstract}
Recently almost all universities in the world have implemented E-learning to support their academic system. Previous studies have been conducted to determine CSF using Analytic Hierarchy Process (AHP) method. However, AHP method cannot handle the uncertainty and vagueness of the human's opinion, so then it causes less appropriate decision. Some researcher has proposed to use fuzzy sets theory with AHP to increase the ability of AHP to deal problem regarding the uncertainty/fuzziness. This study aims to determine ranks of priorities of the multiple factors which influence the E-learning success using FAHP method. The respondents consist of ten e-learning's experts, 305 lecturers, and 4195 students at Sebelas Maret University. The result describes similar success factors ranking between both experienced and nonexperienced user (lecturer and student). Then, the result shows that there are five most influencial success factors of e-learning at Sebelas Maret University based on the lectures perspective Financial Policy, Regulatory Policy, Course quality, Relevant Content and Technical Support. On the other hand, according to the student's point of view five most e-learning, critical success factors are Quality of Course, Relevant of Content, Completeness of Content, Attitudes toward Student, and Flexibility in taking Course. Therefore, this finding can be used by E-learning management of Sebelas Maret University to deteremine a strategy to to achieve successful implementation of e-learning at Sebelas Maret University with consider these factors.
\end{abstract}

\section{Introduction}

Almost all universities in the world have implemented elearning to support their academic system today. There are various advantages of e-learning such as students can complete courses in anytime and anywhere, and enable to choose subjects according to his ability. Moreover, elearning can reduce the costs related to instructor's salaries, classroom, student and lecture travel. Also, students can interact directly with lectures [1]. So, understanding various factors which influence the success of e-learning implementation is important. This study aims to identify the success factors of e-learning programs in Sebelas Maret University from Lecturer and student's perspective.

A literature review of previous research on CSF elearning gives us information that five factors identified as success factors are University Involvement, Quality of Infrastructure and System, Quality of Design, Attitude of Students and Lecturer Toward E-learning.

Previous studies have been conducted to determine CSF using Analytic Hierarchy Process (AHP) method m [1 - 3]. However, AHP method has a drawbacks that AHP can only compute information which has an absolute value and improper to deal the uncertainty value of human subjective judgment cause less precision result of priority ranking [4]. To deal this issue, some researchers suggest to using Fuzzy theory to merge with AHP to improve the ability of AHP to handle uncertainty/Fuzzyness [4 - 8].
This article aims to determine E-learning CSF rankings based on student and lecturer's perception using FuzzyAHP.

\section{Literature Review}

\subsection{E-learning Critical Success Factors}

According to various previous studies, there are many factors influence success of e-learning in the universities as follow

\subsubsection{Universities Involvement}

The involvement of university's management has a significant role in influencing the success of E-learning. This factor consist of a university policies (Financial Policy) $[2,9,10]$, Regulatory policies $[2,9,10]$, Technical Support $[2,9-11]$, Held seminars and training $[2,10]$.

\subsubsection{Quality of Infrastructure and System}

Infrastructure and e-learning system is a major factor in supporting the success of E-learning. This element consists of Level portability products [2, 11], The standard of reliability product $[2,10,11]$, Easy to understand and easy to use $[2,10,11]$, Design and user interface system [2].

\footnotetext{
* Corresponding author: rini.anggrainingsih@,staff.uns.ac.id
} 


\subsubsection{Quality of Design and Material}

Design and good course materials can significantly increase user satisfaction E-learning. This factors consist of Course quality [2, 11, 12], relevant content [2, 11, 12], completeness of content $[2,11,12]$, and Flexibility in taking course $[2,12]$.

\subsubsection{Student's Characteristic}

These factors consist of expertise and insight into the use of computers [2, 12], expertise and insight into the utilization of the internet $[2,12]$, Attitudes toward elearning [2, 12], forum/discussion availability [12].

\subsubsection{Lecture's Characteristic}

Lecture characteristics that affect the success of Elearning, such as attitude towards students [2, 12], timely response [2, 12], liveliness lectures [2, 11, 12], and attitudes toward e-learning $[2,11,12]$.

\subsection{AHP and Fuzzy AHP}

Analytic Hierarchy Process (AHP) is a multicriteria decision-making approach which arranges some relevant decision factors in a hierarchy structure [13]. The international scientific community has accepted AHP method as a robust and flexible multi-criteria decisionmaking tool for dealing complex decision problems [13].

However, there is a drawback of AHP method that AHP is just able to compute an absolute value in number only and does not has adequate to reveal precision decision on a subjective judgment of human [4]. A Fuzzy method is merged with AHP to increase the ability of AHP on uncertainty/Fuzzyness problem [4 - 8].

Fuzzy-AHP is an improvement of AHP method which combines fuzzy theory and AHP method. Fuzzy theory is a theory to overcome the confusion and uncertainty of a judgment [5]. The fuzzy-AHP method can deal vagueness of opinion which cannot be accommodated using AHP only. The uncertainty data can be represented in a fuzzy number, as known as Triangular Fuzzy Number (TFN). TFN denoted by $(l, m, u)$ where $l$ is the possibility of the smallest value, $m$ is the value of the most promising, and $u$ is the opportunity to the greatest value.

AHP method can combine ratings and preferences of individuals and groups who then called AHP Group or AHP Group Decision Making [14]. AHP Group or AHP Group Decision Making is the development of AHP method which is individual. The judgement is not only done by one person but can be several people at once. There are two techniques in the merging of personal preferences in the group [15], there is Aggregation of Individual Judgements (AIJ) and Aggregation of Individual Priorities (AIP).

Aggregation of Individual Judgements (AIJ) method combines a collection of different choices in the group into a single person / single group. Some decision makers made pairwise comparisons are combined into one group pairwise comparisons using the formula (1).

$$
\begin{aligned}
& A^{[G]}=\left(a_{i j}^{[G]}\right), \text { where } a_{i j}^{[G]} \\
& =\prod_{k=1}^{r}\left(a_{i j}^{[k]}\right)^{\beta_{k}}, i, i \in\{1, n\}
\end{aligned}
$$

Where $A^{[G]}$ a new pairwise comparison matrix, $a_{i j}^{[G]}$ he scale of the new interest in the new comparative matrix, $r$ a number of decision-makers, $k$ a number of columns (factors) in the pairwise comparison matrix, $a_{i j}^{[k]}$ the scale of the interests of the individual comparison matrix column $k$, dan $\beta k$ is the weight of the decision maker. If the weight of the decision maker synonymous people who make decisions in the group have the same interests and strengths then $\beta k=1 / r$

Aggregation of Individual Priorities (AIP) is merging technique whereas each preference would be to have each priority alternative. So every person in a group decisionmakers sought alternative weighting of pairwise they make, then the priority weight of each was combined into a priority group. To combine the preferences of each priority person group can use the formula (2).

$$
w_{i}^{[G]}=\prod_{k=1}^{r}\left(w_{i}^{[k]}\right)^{\beta_{k}}
$$

Where $w_{i}^{[G]}$ is a joint priority weight, $r$ a number of decision-makers, $k$ a number of columns (factors) in the priority weighting matrix, and $\beta k$ is the weight of the decision maker. If the weight of the decision maker synonymous people who make decisions in the group have the same interests and strengths then $\beta k=1 / r$.

Technique incorporation of preference on Fuzzy-AHP is calculated by combining pairwise made each person into a matrix of the pairwise group by using the formula (3) [16].

$$
\begin{aligned}
& l_{i j}=\left(\prod_{k=1}^{K} l_{i j k}\right)^{1 / K}, \\
& m_{i j}=\left(\prod_{k=1}^{K} m_{i j k}\right)^{1 / K}, \\
& u_{i j}=\left(\prod_{k=1}^{K} u_{i j k}\right)^{1 / K}
\end{aligned}
$$

Where $l_{i j}$ is $l$ (lowest triangular fuzzy number) in a new row $I$ column $j, K$ is a number of decision-makers. Then, $l_{i j k}$ is $l$ (most inferior triangular fuzzy-number) policymakers to $k$ row $i$ column $j, m_{i j}$ is $m$ (average triangular fuzzy number) of new row $i$ column $j$, and $u_{i j}$ is $u$ (upper triangular fuzzy number) of new row $i$ column $j$. 


\section{Research Method}

This study investigated e-learning CSFs using three sets of a questionnaire for expert, lecturer and student at Sebelas Maret University, Surakarta, Indonesia. The survey was designed as ratio type, whereas the questions consist of factors and subfactors were compared each other one by one. We used Likert scale ratio and weights respectively Strongly Agree (SS), Agree (S), Normal (N), Disagree (TS) and Strongly Disagree (STS ) for five (5), four (4), three (3), two (2) and one (1) respectively.

The questionnaire for experts developed using Google form while questionnaire for students and lecturers was developed using PHP laravel and PostgreSQL. We conducted an online survey on two stages. Firstly, we conducted survey for ten e-learning expert which consists of ten statements to obtain weight and rank of five factors that identified as e-learning success factors namely; University Involvement (A), Quality of Infrastructure and System (B), Quality of Design (C), Attitude of Students and Lecturer Toward E-learning (D \& E). E-learning experts are both lecturer and technician of Sebelas Maret University who have experience in managing online class as an admin and who have experience research in elearning topic.

Table 2. E-learning critical success factors \& subfactors

\begin{tabular}{|c|c|c|c|}
\hline No & Sub-Factor & Code & Reference \\
\hline \multicolumn{4}{|c|}{ University Involvement (A) } \\
\hline 1 & University's (Financial Policy) & Sub F 1 & {$[2,9,10]$} \\
\hline 2 & Universities Policies (Regulatory Policy) & Sub F 2 & {$[2,9,10]$} \\
\hline 3 & Technical Support & Sub F 3 & $\begin{array}{l}{[2,9,10,} \\
11]\end{array}$ \\
\hline 4 & Seminars and Training Availability & Sub F 4 & {$[2,10]$} \\
\hline \multicolumn{4}{|c|}{ Quality of Infrastructure and Systems (B) } \\
\hline 5 & The level of portability products & Sub F 5 & {$[2,11]$} \\
\hline 6 & The level of product reliability & Sub F 6 & {$[2,10,11]$} \\
\hline 7 & Easy to understand \& easy to use & Sub F 7 & {$[2,10,11]$} \\
\hline 8 & Design and user interface system & Sub F 8 & {$[2]$} \\
\hline \multicolumn{4}{|c|}{ Quality of Design and Courses (C) } \\
\hline 9 & Course quality & Sub F 9 & {$[2,11,12]$} \\
\hline 10 & Relevant Content & Sub F 10 & {$[2,11,12]$} \\
\hline 11 & Completeness of Content & Sub F 11 & {$[2,11,12]$} \\
\hline 12 & Flexibility in taking Course & Sub F 12 & {$[2,12]$} \\
\hline \multicolumn{4}{|c|}{ Student's Characteristics (D) } \\
\hline 13 & Expertise and insight to use a computer & Sub F 13 & {$[2,12]$} \\
\hline 14 & Expertise and insight to use the internet & Sub F 14 & {$[2,12]$} \\
\hline 15 & Attitudes toward e-learning & Sub F 15 & {$[2,12]$} \\
\hline 16 & Forum / discussion availability & Sub F 16 & {$[12]$} \\
\hline \multicolumn{4}{|c|}{ Lecture's Characteristics (E) } \\
\hline 17 & Attitudes toward Student & Sub F 17 & {$[2,12]$} \\
\hline 18 & Timely response & Sub F 18 & {$[2,12]$} \\
\hline 19 & liveliness lectures & Sub F 19 & {$[2,11,12]$} \\
\hline 20 & Attitudes toward e-learning & Sub F 20 & {$[2,11,12]$} \\
\hline
\end{tabular}

Then, the second survey was conducted to find weight and rank of subfactors of five e-learning success factors as shown in Table 2 from lecturer and student point of view. Whereas, the lecturers gave 30 statements of questions while the students were given 18 statements of questions.

The application of survey was life online at http://survey.uns.ac.id/elearning. Then, the collected data was calculated using the Fuzzy-AHP application as following steps. First, make a pairwise comparison group using Aggregation of Individual Judgements (AIJ), then determined the fuzzy weight and defuzzification and normalised using formula (1) (2) and (3).

\section{Result and Discussion}

We ran Survey application from 31 October to 21 November 2016 and obtained 10 data from e-learning expert of Sebelas Maret University Surakarta and 305 lecturers and 4195 students who answered questionnaire completely (as shown in Table 3, 4, 5). The lectures consist of 93 experienced lecturers and 212 nonexperienced on e-learning, while the students consist of 1370 students experienced and 2825 non-experienced students on e-learning.

Table 3. Survey result for e-learning expert at UNS

\begin{tabular}{|l|c|c|c|c|c|}
\hline \multirow{2}{*}{ Factors Compared } & $\mathbf{1}$ & $\mathbf{2}$ & $\mathbf{3}$ & $\mathbf{4}$ & $\mathbf{5}$ \\
\cline { 2 - 6 } & STS & TS & $\mathbf{N}$ & $\mathbf{S}$ & SS \\
\hline A more important than B & 0 & 1 & 1 & 4 & 4 \\
\hline A more important than C & 0 & 3 & 1 & 6 & 0 \\
\hline A more important than D & 0 & 1 & 2 & 7 & 0 \\
\hline A more important than E & 0 & 0 & 5 & 5 & 0 \\
\hline B more important than C & 1 & 5 & 3 & 1 & 0 \\
\hline B more important than D & 0 & 2 & 3 & 3 & 2 \\
\hline B more important than E & 0 & 6 & 0 & 3 & 1 \\
\hline C more important than D & 0 & 2 & 3 & 1 & 4 \\
\hline C more important than E & 0 & 2 & 2 & 4 & 2 \\
\hline D more important than E & 0 & 4 & 2 & 4 & 0 \\
\hline
\end{tabular}

Table 4. Survey result for lecturers

\begin{tabular}{|c|c|c|c|c|c|}
\hline \multirow{2}{*}{ Subfactor Compared } & 1 & 2 & 3 & 4 & 5 \\
\hline & STS & TS & $\mathbf{N}$ & $\mathbf{S}$ & SS \\
\hline 1 more important than 3 & 22 & 41 & 78 & 131 & 33 \\
\hline 1 more important than 4 & 22 & 42 & 88 & 124 & 29 \\
\hline 2 more important than 3 & 21 & 49 & 94 & 113 & 28 \\
\hline 2 more important than 4 & 17 & 40 & 102 & 116 & 30 \\
\hline 3 more important than 4 & 14 & 39 & 120 & 107 & 25 \\
\hline 5 more important than 6 & 17 & 36 & 104 & 115 & 33 \\
\hline 5 more important than 7 & 11 & 17 & 84 & 139 & 54 \\
\hline 5 more important than 8 & 9 & 17 & 98 & 128 & 53 \\
\hline 6 more important than 7 & 8 & 18 & 105 & 128 & 46 \\
\hline 6 more important than 8 & 7 & 13 & 93 & 135 & 57 \\
\hline 7 more important than 8 & 7 & 12 & 113 & 131 & 42 \\
\hline 9 more important than 10 & 9 & 5 & 96 & 144 & 51 \\
\hline 9 more important than 11 & 19 & 39 & 130 & 97 & 20 \\
\hline 9 more important than 12 & 12 & 31 & 122 & 109 & 31 \\
\hline 10 more important than 11 & 15 & 61 & 134 & 81 & 14 \\
\hline 10 more important than 12 & 11 & 26 & 126 & 109 & 33 \\
\hline 11 more important than 12 & 15 & 44 & 133 & 96 & 17 \\
\hline 13 more important than 14 & 15 & 20 & 136 & 105 & 29 \\
\hline 13 more important than 15 & 8 & 26 & 107 & 132 & 32 \\
\hline
\end{tabular}




\begin{tabular}{|c|c|c|c|c|c|}
\hline \multirow{2}{*}{ Subfactor Compared } & 1 & 2 & 3 & 4 & 5 \\
\hline & STS & TS & $\mathbf{N}$ & $\mathbf{S}$ & SS \\
\hline 13 more important than 16 & 6 & 8 & 90 & 148 & 53 \\
\hline 14 more important than 15 & 7 & 21 & 111 & 135 & 31 \\
\hline 14 more important than 16 & 4 & 11 & 100 & 144 & 46 \\
\hline 15 more important than 16 & 8 & 17 & 127 & 125 & 28 \\
\hline 17 more important than 18 & 5 & 6 & 98 & 149 & 47 \\
\hline 17 more important than 19 & 11 & 27 & 125 & 117 & 25 \\
\hline 17 more important than 20 & 11 & 27 & 127 & 115 & 25 \\
\hline 18 more important than 19 & 12 & 32 & 121 & 112 & 28 \\
\hline 18 more important than 19 & 8 & 17 & 124 & 126 & 30 \\
\hline 18 more important than 20 & 9 & 19 & 142 & 100 & 35 \\
\hline 19 more important than 20 & 6 & 28 & 139 & 105 & 27 \\
\hline
\end{tabular}

Table 5. Survey result for students

\begin{tabular}{|l|l|l|l|l|l|}
\hline Subfactor Compared & $\mathbf{1}$ & $\mathbf{2}$ & $\mathbf{3}$ & $\mathbf{4}$ & $\mathbf{5}$ \\
\cline { 2 - 6 } & STS & TS & N & S & SS \\
\hline 5 more important than 7 & 211 & 260 & 1645 & 1590 & 489 \\
\hline 5 more important than 8 & 201 & 265 & 1690 & 1537 & 502 \\
\hline 6 more important than 7 & 192 & 174 & 1726 & 1532 & 571 \\
\hline 6 more important than 8 & 209 & 182 & 1745 & 1523 & 536 \\
\hline 7 more important than 8 & 190 & 161 & 1726 & 1584 & 534 \\
\hline 9 more important than 10 & 186 & 249 & 1730 & 1498 & 532 \\
\hline 9 more important than 11 & 191 & 448 & 1796 & 1305 & 455 \\
\hline 9 more important than 12 & 202 & 359 & 1885 & 1311 & 438 \\
\hline 10 more important than 11 & 173 & 340 & 1848 & 1377 & 457 \\
\hline 10 more important than 12 & 175 & 265 & 1933 & 1396 & 426 \\
\hline 11 more important than 12 & 169 & 220 & 1918 & 1428 & 460 \\
\hline 17 more important than 18 & 235 & 164 & 1780 & 1430 & 586 \\
\hline 17 more important than 19 & 231 & 171 & 1867 & 1428 & 498 \\
\hline 17 more important than 20 & 219 & 218 & 1894 & 1341 & 523 \\
\hline 18 more important than 19 & 221 & 155 & 1926 & 1388 & 505 \\
\hline 18 more important than 20 & 217 & 162 & 1979 & 1367 & 470 \\
\hline 19 more important than 20 & 246 & 251 & 2052 & 1205 & 441 \\
\hline
\end{tabular}

Then, employed Fuzzy-AHP method to compute the data and rank the influence e-learning success factors. To make computation process easier, we designed an application program to apply Fuzzy-AHP algorithm using PHP laravel and PostgreSQL as a database. While weight for each factor was changed to the fuzzy-AHP ratio scale as seen in Table 6

Table 6. The Fuzzy-AHP proportion [5]

\begin{tabular}{|l|l|l|}
\hline Ratio & $\begin{array}{l}\text { Triangular } \\
\text { fuzzy Scale }\end{array}$ & $\begin{array}{l}\text { Triangular fuzzy } \\
\text { Scale (Reciprocal) }\end{array}$ \\
\hline Normal (N) & $(1,1,1)$ & $(1 / 1,1 / 1,1 / 1)$ \\
\hline Disagree (TS) & $(1 / 7,1 / 5,1 / 3)$ & $(3,5,7)$ \\
\hline Strongly Disagree (STS) & $(1 / 9,1 / 7,1 / 5)$ & $(5,7,9)$ \\
\hline Agree (S) & $(3,5,7)$ & $(1 / 7,1 / 5,1 / 3)$ \\
\hline Strongly Agree (SS) & $(5,7,9)$ & $(1 / 9,1 / 7,1 / 5)$ \\
\hline
\end{tabular}

The calculation result for expert point of view shown in Table 7. According to Table 7, we get information that the most important factor is 'University Involvement' then, the second is 'Quality of design and courses' following by 'Lecturer's Characteristic', 'Quality of Infrastructure and System' and 'Student's Characteristics'.
Table 7. E-learning success factors ranking based on expert perception

\begin{tabular}{|l|c|}
\hline Factor & Ranking \\
\hline University Involvement & 1 \\
\hline Quality Of Infrastructure and Systems & 4 \\
\hline Quality Of Design and Courses & 2 \\
\hline Student's Characteristics & 5 \\
\hline Lecture's Characteristics & 3 \\
\hline
\end{tabular}

Table 8 illustrates the calculation results of critical elearning priority from a lecturer who has both e-learning experienced and non-e-learning experienced lecturers point of views. Table 8 shows that both experienced and non-experienced lecture have similar notion that there are five essential sub-factors for e-learning success 'Financial Policy', 'Regulation Policy', 'Technical Support', 'Course Quality' and 'Relevant Content'. Both experienced and non-experienced lecture agreed that the most important factor is university policy (financial policy and regulation policy).

Table 8. The Priority of e-learning success factor based on lecturers point of view

\begin{tabular}{|l|c|c|}
\hline Subfactor & $\begin{array}{c}\text { Exp } \\
\text { Lecture }\end{array}$ & $\begin{array}{c}\text { Non-exp } \\
\text { Lecture }\end{array}$ \\
\hline University Policies (Financial Policy) & 1 & 1 \\
\hline University Regulation (Regulation Policy) & 2 & 2 \\
\hline Technical Support & 4 & 3 \\
\hline Seminars and Training Availability & 6 & 6 \\
\hline Portability products & 8 & 8 \\
\hline Reliability product & 13 & 13 \\
\hline Easy to understand and easy to use & 16 & 17 \\
\hline Design and user interface system & 20 & 19 \\
\hline Course quality & 3 & 4 \\
\hline Relevant Content & 5 & 5 \\
\hline Completeness of Content & 9 & 7 \\
\hline Flexibility to taking Course & 10 & 10 \\
\hline Expertise to use a computer & 11 & 9 \\
\hline Expertise to use the internet & 14 & 14 \\
\hline Attitudes toward e-learning & 18 & 18 \\
\hline Forum / discussion availability & 19 & 20 \\
\hline Attitudes toward Student & 7 & 11 \\
\hline Respond time & 12 & 12 \\
\hline liveliness lectures & 15 & 15 \\
\hline Attitudes toward e-learning & 17 & 16 \\
\hline
\end{tabular}

Then, calculations results of critical subfactors of elearning priority according to students point of view as shown in Table 9.

Table 9. Calculations results of critical e-learning priority according to students point of view

\begin{tabular}{|l|l|l|}
\hline Subfactor & $\begin{array}{l}\text { Exp } \\
\text { Student }\end{array}$ & $\begin{array}{l}\text { Non-Exp } \\
\text { Student }\end{array}$ \\
\hline $\begin{array}{l}\text { The level of portability } \\
\text { products }\end{array}$ & 6 & 6 \\
\hline The level of product reliability & 8 & 8 \\
\hline $\begin{array}{l}\text { Easy to understand and easy to } \\
\text { use }\end{array}$ & 10 & 11 \\
\hline $\begin{array}{l}\text { Design and user interface } \\
\text { system }\end{array}$ & 12 & 12 \\
\hline Course quality & 1 & 1 \\
\hline
\end{tabular}




\begin{tabular}{|l|l|l|}
\hline Subfactor & $\begin{array}{l}\text { Exp } \\
\text { Student }\end{array}$ & $\begin{array}{l}\text { Non-Exp } \\
\text { Student }\end{array}$ \\
\hline Relevant Content & 2 & 3 \\
\hline Completeness of Content & 3 & 2 \\
\hline Flexibility in taking Course & 4 & 4 \\
\hline Attitudes toward Student & 5 & 5 \\
\hline Timely response & 7 & 7 \\
\hline liveliness lectures & 9 & 10 \\
\hline Attitudes toward e-learning & 11 & 9 \\
\hline
\end{tabular}

Table 9 describes that both experienced and not experienced students on e-learning have similar notion that the most five e-learning CSFs are subfactors 'Course quality', Relevant Content, Completeness of Content, Flexibility in taking Course, and Lecture's Attitudes toward Student. Then, both experienced and nonexperienced student agreed that the most important elearning success subfactor is 'Course Quality'.

\section{Conclusion}

Based on the research, we conclude that both experienced and non-experienced e-learning user have similar notion about e-learning critical success factor as follows

- Five factors that most influence the CSF E-learning UNS according to the lectures perception are Financial Policy, Regulatory Policy, Course quality, Relevant Content and Technical Support

- Five factors that most influence the CSF E-learning UNS based on students point of view are Course quality, Relevant Content, Completeness of Content, Attitudes toward Student, and Flexibility in taking Course

Therefore, this finding can be used by E-learning management of Sebelas Maret University to determine a strategy to achieve successful implementation of elearning at Sebelas Maret University with considering these factors.

\section{References}

1. Gautam, S. and M.K. Tiwari, Components and benefits of E-learning system. 2014.

2. Bhuasiri, W., et al., Critical success factors for elearning in developing countries: A comparative analysis between ICT experts and faculty. Computers \& Education, 2012. 58(2): p. 843-855.

3. Anggrainingsih, Rini, et al. "Determining elearning critical success factor at sebelas maret university using Analytical Hierarchy Process (AHP)." Technology of Information and Communication (ISemantic), International Seminar on Application for. IEEE, 2016.

4. Ayhan, M.B., A Fuzzy AHP approach for supplier selection problem: a case study in a gear motor company. arXiv preprint arXiv:1311.2886, 2013.

5. Kabir, G. and A. Akhtar Hasin, Evaluation of customer oriented success factors in mobile commerce using fuzzy AHP. Journal of Industrial
Engineering and Management, 2011. 4(2): p. 361386.

6. Kimiafar, K., et al., Prioritizing factors influencing nurses' satisfaction with hospital information systems: a fuzzy analytic hierarchy process approach. CIN: Computers, Informatics, Nursing, 2014. 32(4): p. 174-181.

7. Zain, D. and B. Santoso, Determination of Naval Based Locations: Strategy to Maximize Performance Monitoring of Defense and Security Systems in The Sea (Study on Maritime Security and Defense Systems in Indonesia). Jurnal Aplikasi Manajemen, 2011. 9(1): p. 254-263.

8. Tiznado, M. and L. Pradenas, LOCATION OF PREHOSPITAL CARE BASIS THROUGH COMBINED FUZZY AHP AND GIS METHOD. 2014.

9. Biškupić, I.O., S. Lacković, and K. Jurina, Successful and Proactive e-learning Environment Fostered by Teachers' Motivation in Technology Use. ProcediaSocial and Behavioral Sciences, 2015. 174: p. 36563662.

10. McGill, T.J., J.E. Klobas, and S. Renzi, Critical success factors for the continuation of e-learning initiatives. The Internet and Higher Education, 2014. 22: p. 24-36.

11. Lwoga, E.T., Critical success factors for adoption of web-based learning management systems in Tanzania. International Journal of Education and Development using Information and Communication Technology, 2014. 10(1): p. 4.

12. Chow, W.S. and S. Shi, Investigating students' satisfaction and continuance intention toward elearning: An Extension of the expectationconfirmation model. Procedia-Social and Behavioral Sciences, 2014. 141: p. 1145-1149.

13. Srdevic, Z., B. Blagojevic, and B. Srdevic, AHP based group decision-making in ranking loan applicants for purchasing irrigation equipment: a case study. Bulgarian Journal of Agricultural Science, 2011. 17(4): p. 531-543.

14. Huong, N.Q., COMBINING AHP GROUP ANALYSIS AND GIS IN VULNERABILITY ASSESSMENT OF PROTECTED AREA IN VIETNAM. 2014.

15. Ssebuggwawo, D.D., S.S. Hoppenbrouwers, and H.E. Proper, Group Decision Making in Collaborative Modeling. 2010.

16. Meixner, O., Fuzzy AHP group decision analysis and its application for the evaluation of energy sources. Institute of Marketing and Innovation. Vienna, Austria, 2009.

17. Abdullah, L., Ranking of the factors associated with road accidents using correlation analysis and fuzzy TOPSIS. 2010.

18. Govindan, K., A. Diabat, and K.M. Shankar, Analyzing the drivers of green manufacturing with 
fuzzy approach. Journal of Cleaner Production, 2015. 96: p. 182-193.

19. Astuty, W., An Analysis on the Impact of Participatory Budgeting and Procedural Fairness Toward Manager's Commitment and Performance. Global Journal of Management And Business Research, 2015. 14(5).

20. Chakraborty, R., A. Ray, and P. Dan, Multi criteria decision making methods for location selection of distribution centers. International Journal of Industrial Engineering Computations, 2013. 4(4): p. 491-504.

21. Hussain, N. and S. Subramoniam, Ranking Critical Success Factors of Healthcare Management Information Systems using AHP. 2014, ISAHP. 